\title{
Anti-phytoplankton therapy of finfish: the mucolytic agent L-cysteine ethyl ester protects coho salmon Oncorhynchus kisutch against the harmful phytoplankter Chaetoceros concavicornis
}

\author{
C. Z. Yang, L. J. Albright \\ Institute for Aquaculture Research, Department of Biological Sciences, Simon Fraser University, Burnaby, British Columbia, \\ Canada V5A 1S6
}

\begin{abstract}
The harmful diatoms Chaetoceros concavicornis and $C$. convolutus will kill salmonids such as rainbow trout Oncorhynchus mykiss and coho salmon $O$. kisutch if present at as few as 5 cells $\mathrm{ml}^{-1}$ seawater. Our previous research has shown that the barbed spines of these diatoms become wedged between the secondary lamellae of salmonids, where they cause excessive production of mucus by goblet cells. This mucus and the diatoms accumulate on and between the secondary lamellae to such an extent that the fish suffocate. A class of pharmacologically active compounds (mucolytic agents, e.g. L-cysteine ethyl ester) exists which decrease mucus production in mammals and humans when ingested. When coho salmon ingest this agent at up to $12 \mathrm{mg} \mathrm{kg}^{-1}$ biomass $\mathrm{d}^{-1}$, mucus synthesis is reduced to such an extent that an accumulation of this material does not occur on and between the secondary lamellae; the fish remain viable in what would otherwise be a lethal exposure to $C$. concavicornis cells
\end{abstract}

KEY WORDS: Anti-phytoplankton therapy - Mucolytic agent - Mucus - L-cysteine ethyl ester · Harmful phytoplankton S Salmon · Chaetoceros concavicomis

\section{INTRODUCTION}

In many regions of the world, finfish have been killed by harmful or toxic phytoplankters where they are farmed in coastal seawaters. Along the west coast of Canada and the northwest coast of the United States, there are 3 species of phytoplankters which most commonly kill penned salmonids. These are Chaetoceros concavicornis, C. convolutus and Heterosigma akashiwo (Gaines \& Taylor 1986). Black (1991) has estimated that between 1986 and 1990 these phytoplankters killed between Can $\$ 0.5$ and 4.2 million of farmed salmon annually along the British Columbia coast. Horner et al. (1991) estimated that toxic and harmful phytoplankton blooms in coastal seawaters of Washington State, USA, have killed more than 2 million farmed salmon, with monetary losses of approximately U.S.\$10 million, in the period 1988 through 1990.
Measures to control phytoplankton-related finfish mortalities have been largely focused towards avoidance of culturing these fish in seawaters which are prone to harmful or toxic phytoplankton blooms. To date, control measures other than this are not available.

Chaetoceros concavicornis and C. convolutus are diatoms which possess siliconaceous spines which may be up to $200 \mu \mathrm{m}$ in length. Along the length of each spine are numerous barbs. As water passes over the gills of finfish, the spined and barbed diatoms become trapped in large 'windrow-like' masses between the secondary lamellae (Fig. 1). These masses of spined and barbed diatoms irritate the goblet cells of the respiratory epithelium such that there is an accumulation of an excessive amount of mucus which restricts dissolved oxygen uptake (Yang \& Albright 1992). If the uptake of oxygen is sufficiently restricted the fish dies (Yang \& Albright 1992). C. concavicornis and $C$. convolutus can be overtly lethal 


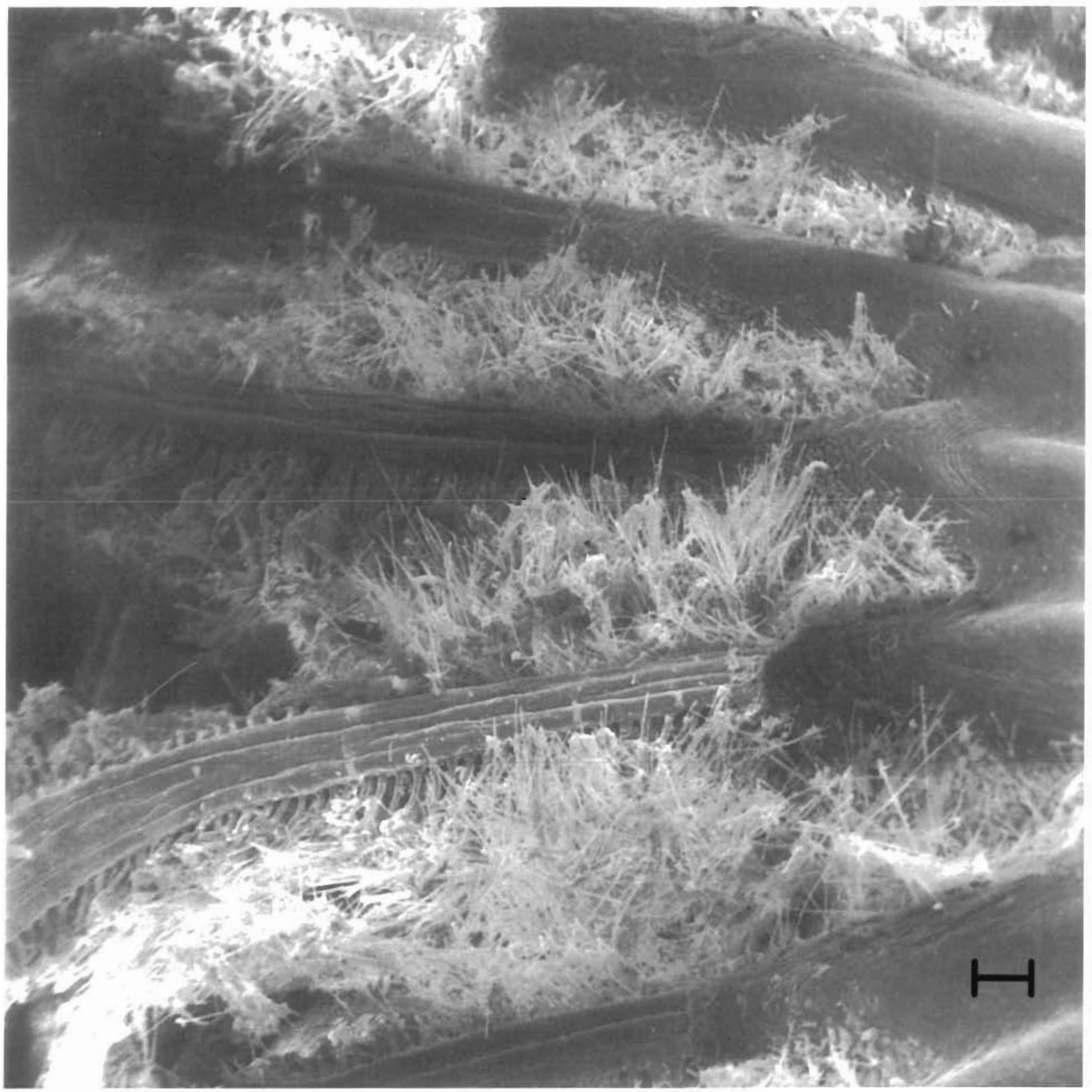

Fig. 1. Oncorhynchus kisutch. Scanning electron microscopic view of the primary and secondary lamellae of a juvenile coho salmon exposed to approximately 50 cells of Chaetoceros concavicornis ml seawater for $72 \mathrm{~h}$. Scale bar $=100 \mu \mathrm{m}$

to penned salmon at concentrations as low as 5 cells $\mathrm{ml}^{-1}$ (Bell et al. 1974) and exacerbate pathogenrelated mortalities at sublethal doses (Albright et al. 1993).

Mortalities related to excessive mucus production and accumulation on respiratory epithelia, from whatever cause, are also experienced by other animals such as rats and canines (Lightowler \& Lightowler 1971, Martin et al. 1980, Servin et al. 1988, Ueno et al. 1989). Humans may also experience respiratory dysfunction due to overproduction and accumulation of mucus in lungs (Aylward et al. 1980).

A class of therapeutic drugs has been identified which alleviates diseases associated with excessive production and accumulation of mucus in the respiratory tract of domestic animals and humans. These are termed mucolytic agents. When administered orally to felines, canines and humans, they limit production of mucus in lungs, probably by acting as competitive inhibitors of mucus synthesis (e.g. Sheffner 1963, Martin et al. 1980). 
When administered onto the lung surfaces as an aerosol, some mucolytic agents act as reducing agents, by cleaving $s-s$ bonds of the mucus mucopolysaccharide strands (e.g. Majima et al. 1989). In this way the viscosity of the mucus is reduced. An example of such a mucolytic agent is L-cysteine ethyl ester.

Since goblet cells of teleost fish function in a way similar to those of mammals (Bird \& Eble 1979), we felt that there was a good likelihood that a material such as L-cysteine ethyl ester may act as a mucolytic agent in salmon, as it does in mammals. Accordingly, we report here on the ability of: (1) L-cysteine ethyl ester to suppress mucus accumulation on the secondary lamellae of coho salmon and (2) the ability of these same L-cysteine ethyl ester-treated salmon to survive what would otherwise be a lethal challenge with Chaetoceros concavicornis.

\section{MATERIALS AND METHODS}

The culture of Chaetoceros concavicornis was obtained from the Northeast Pacific Culture Collection. Dept of Oceanography, University of British Columbia (B.C.). This harmful diatom was cultured using several 1 l quantities of Harrison's medium (Harrison et al. 1980) each contained in 2 l Fernback flasks at a temperature of $14^{\circ} \mathrm{C}$ and a $14 \mathrm{~h}$ light: $10 \mathrm{~h}$ dark cycle. Cell concentrations were determined using the Utermöhl (1958) technique.

Coho salmon Oncorhynchus kisutch (mean weight $12 \mathrm{~g}$ ) were obtained from the Capilano Fish Hatchery, Canada Dept of Fisheries and Oceans, West Vancouver, B.C. These fish were transported to Simon Fraser University and maintained in aerated seawater (salinity 10\%). At $30 \mathrm{~d}$ prior to the experiment, 200 fish were randomly divided into 4 groups of 50 fish each; each group was placed in a 200 l oval tank containing $100 \mathrm{l}$ of seawater of $10 \%$ salinity, $\mathrm{pH} 6.7$ to 7.5 , temperature 17.5 to $18.0^{\circ} \mathrm{C}$ and oxygen content 10.0 to $10.5 \mathrm{mg} \mathrm{l}^{-1}$.

L-cysteine ethyl ester (Sigma, St. Louis, MO, USA) was weighed and sprinkled onto standard fish feed pellets of $2 \mathrm{~mm}$ diameter such that final concentrations of $0.3,0.6$ and $0.9 \mathrm{mg}$ L-cysteine ethyl ester $\mathrm{g}^{-1}$ of feed were attained. This treated feed was then mixed with several $\mathrm{ml}$ of herring oil such that the L-cysteine ethyl ester coated the pellets. The treated feed was stored at $5^{\circ} \mathrm{C}$ until used.

The fish in tanks $1,2,3$ and 4 were fed with $8.0 \mathrm{~g} \mathrm{~d}^{-1}$ $\left(1.33 \%\right.$ body weight $\left.\mathrm{d}^{-1}\right)$ of feed containing $0,0.3,0.6$ and $0.9 \mathrm{mg}$ L-cysteine ethyl ester $\mathrm{g}^{-1}$ feed respectively from $3 \mathrm{~d}$ prior to initiating the experiment (time 0 ) and for $2 \mathrm{~d}$ thereafter (Day 2). During this period, the fish in tanks 2, 3 and 4 ingested 4, 8, and $12 \mathrm{mg}$ L-cysteine ethyl ester $\mathrm{kg}^{-1}$ body weight $\mathrm{d}^{-1}$ respectively. From Day 3 through Day 4, all fish were fed with a feed without L-cysteine ethyl ester

On Day 0, Chaetoceros concavicornis was added to the water in all tanks such that the concentrations were maintained between 40 and 54 cells $\mathrm{ml}^{-1}$ for $4 \mathrm{~d}$.

Gill arches were removed from moribund coho in tanks 1 to 3 and coho randomly selected from tank 4 . Following incision, the gill arches were immediately immersed in $2.5 \%$ glutaraldehyde in a $0.1 \mathrm{M} \mathrm{Na}$ cacodylate buffer containing $2 \%(\mathrm{w} / \mathrm{v})$ alcian blue (BDH, Toronto) (Powell et al. 1992). Tissues were maintained at room temperature in the fixative for $24 \mathrm{~h}$ and then dehydrated in ethanol, embedded in paraffin wax, sectioned, stained with Giemsa and examined by light microscopy.

\section{RESULTS}

A total of $37,8,0$ and 1 coho died in tanks $1,2,3$ and 4 in which the fish were fed with $0,4,8$ and $12 \mathrm{mg}$ L-cysteine ethyl ester $\mathrm{kg}^{-1}$ biomass $\mathrm{d}^{-1}$ respectively during the $5 \mathrm{~d}$ treatment with Chaetoceros concavicornis (Fig. 2). The cumulative mortalities of the coho in tanks 1,2, 3 and 4 were $57,12,0$ and $2 \%$ repectively by Day 4 following their exposure to $C$. concavicornis.

A thick mucous layer overlaid the epithelia of the secondary lamellae of the coho treated with Chaetoceros concavicornis only, and a great deal of mucus accumulated between the adjacent secondary lamellae of these salmon (Fig. 3A, B). However, only a thin layer of mucus was observed on the epithelia of the secondary lamellae of control coho which were not exposed to cells of $C$. concavicornis and little or no

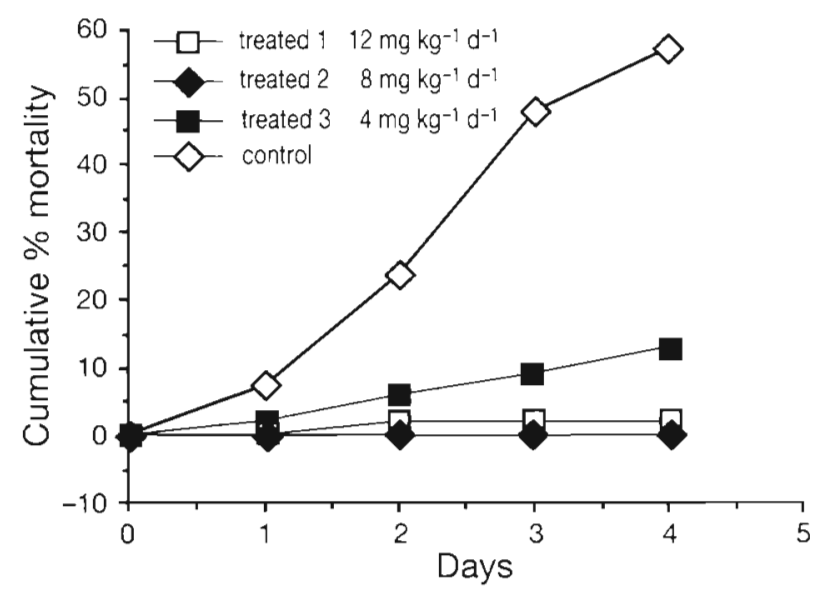

Fig. 2. Onchorhynchus kisutch. Cumulative mortalities of coho salmon (10 to $16 \mathrm{~g}$ ) fed with $12,8,4$ or $0 \mathrm{mg}$ L-cysteine ethyl ester $\mathrm{kg}^{-1}$ biomass $\mathrm{d}^{-1}$ in the presence of between

40 and 54 cells of Chaetoceros concavicornis $\mathrm{ml}^{-1}$ water 


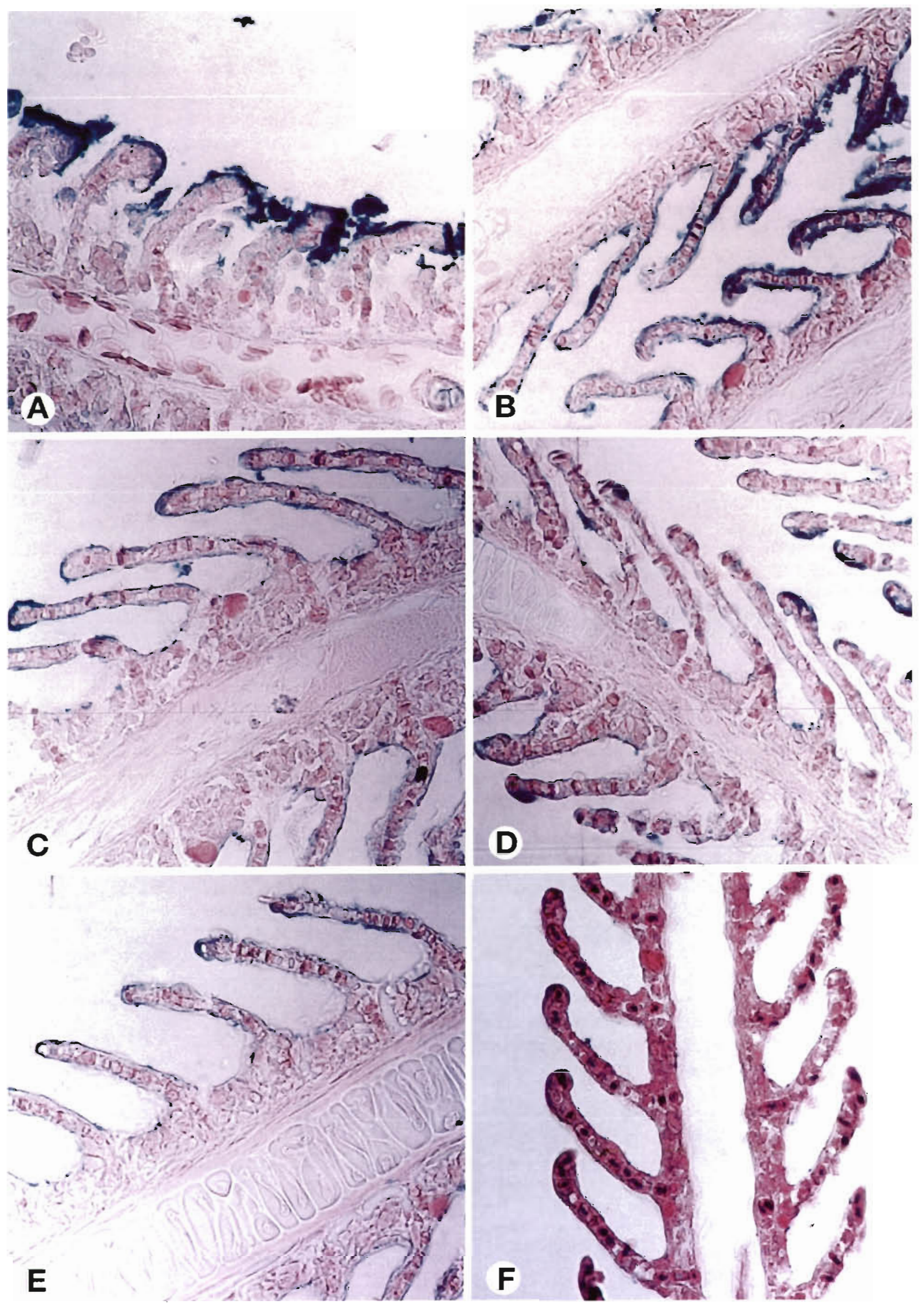


Fig. 3. Onchorhynchus kisutch. Light microscopic views of $6 \mu \mathrm{m}$ thick sections of alcian-blue-stained secondary lamellae of coho salmon: (A, B) treated with Chaetoceros concavicornis only; $(C, D)$ treated with $C$. concavicomis and L-cysteine ethyl ester; $(E, F)$ untreated

mucus was observed between adjacent lamellae of these fish (Fig. 3E, F). Similar small amounts of mucus were observed on the secondary lamellae of the coho treated with both L-cysteine ethyl ester and $C$. concavicornis (Fig. 3C, D)

\section{DISCUSSION}

Mucus is a term used to describe the secondary products of particular organs of animals with specific reference to products of mucous, goblet and serous cells (Charman et al. 1974). Mucus is a proteinaceous material which consists mainly of mucopolysaccharides, with the long, interconnected, fibrous molecules occurring within a gel (Ziment 1978). The physical properties of mucous secretions are largely determined by the high molecular weight glycoproteins which consist of a protein backbone with many oligosaccharide side chains, often called mucin. The peptide chain of mucin contains some non-glycosylated regions; these regions contain many cysteine residues. Many mucous glycoproteins are composed of polymerized glycoprotein subunits through the formation of disulfide bonds in the non-glycosylated region of each protein core, probably involving interaction between adjacent cysteine residues (Allen 1978) which results in a network of matted molecules. Other intermolecular bonds, such as ionic and hydrogen bonds as well as London-van der Waals forces, also bind glycoprotein subunits to each other (Majima et al. 1989).

In many respiratory diseases, the goblet cells increase in number and perhaps in activity (Ziment 1978). As a result, an excessive amount of viscous mucus is secreted. Unfortunately, the goblet cells do not appear to be under nervous or hormonal control, and therefore, they are not readily susceptible to pharmacologic therapy (Ziment 1978). The overactivity of goblet cells appears to be a direct consequence of irritation (Ziment 1978).

Sheffner (1963) reported that the L-cysteine analogue, N-acetylcysteine, was able to decrease human nasal mucus viscosity in vitro by reducing disulfide bonds of adjacent glycoproteins. Subsequent studies have confirmed this property (e.g. Lightowler \& Lightowler 1971, Walters et al. 1985). N-acetylcysteine can also break the disulfide cross-linkage between proteins and DNA in the mucus by virtue of its free sulfhydryl group (Ziment 1978).
When ingested by humans (Aylward et al. 1980) and canines (Martin et al. 1980) N-acetylcysteine decreases the production and secretion of mucus by goblet cells. In addition, it also appears to be able to reduce disulfide bonds and break the macromolecular glycoprotein to smaller subunits when administered topically (Ueno et al. 1989). Cotgreave et al. (1987) proposed that $\mathrm{N}$-acetylcysteine depresses mucus production by increasing the synthesis of glutathione.

When $\mathrm{N}$-acetylcysteine reacts with mucoproteins, it decomposes to acetate and cysteine with liberation of hydrogen sulfide. The free sulfhydryl group of cysteine reacts with the disulfide bridges of mucoprotein, thereby breaking down the complex protein network into less viscous strands (Ziment 1978). Breakage of disulfide bonds results in a marked decrease in the viscosity of mucus; the most successful mucolytic agents that have been investigated appear to produce their effects by this mechanism (Ziment 1978).

The important mucolytic agents are cysteine analogues such as $\mathrm{N}$-acetylcysteine and L-cysteine ethyl ester (Martin et al. 1980, Flora et al. 1985, Servin et al. 1988, Majima et al. 1989). N-acetylcysteine has an undesirable feature in that it possesses a strong odor, whereas L-cysteine ethyl ester is odorless. Because finfish, including salmonids, have a strong olfactory avoidance response to certain odors, we decided to use L-cysteine ethyl ester as a mucolytic agent in the experiments described here.

The data show that L-cysteine ethyl ester suppresses mucus production and accumulation by the cells of the secondary lamellae of coho (Fig. 2). The specific cellular activity which is most likely inhibited by this therapeutant is the mucus secretory activity of the goblet cells of this tissue since mucolytic agents such as L-cysteine ethyl ester competitively inhibit mucus synthesis. The decomposition of mucoprotein likely resulted in a mucus of lower viscosity which was more easily washed off the primary and secondary lamellae by water passing over the gills of the fish.

Our data show that partial protection from the harmful effects of Chaetoceros concavicornis occurred at ingestion rates of L-cysteine ethyl ester of 4 and $8 \mathrm{mg}$ $\mathrm{kg}^{-1}$ biomass $\mathrm{d}^{-1}$ and complete protection occurred at $12 \mathrm{mg} \mathrm{kg}^{-1}$ biomass $\mathrm{d}^{-1}$ (Fig. 1). Based upon these observations, it would appear that the most effective dosage is somewhere between 8 and $12 \mathrm{mg}$ L-cysteine ethyl ester $\mathrm{kg}^{-1} \mathrm{~d}^{-1}$. 
The mucolytic agent L-cysteine ethyl ester is not destroyed by the temperature conditions used to produce commercial fish feed pellets, and the material is quite stable in the pellets. There is therefore a good possibility that treatment of farmed salmonids in seawater pens undergoing an exposure to harmful blooms of Chaetoceros concavicornis and/or C. convolutus with mucolytic-agent-treated feed would be effective in controlling mortality rates under farming conditions. It is aiso possible that the use of mucolytic agents in feed or water may be used to limit mucus accumulation on gills of aquatic animals such as finfish under conditions which would cause the excess production of this material by the animal, for example irritating chemicals in the water and bacterial gill disease.

Acknowledgements. We are grateful to the Canada Dept of Fisheries and Oceans for the donation of approximately 500 coho fingerlings. This research was supported by a Natural Sciences and Engineering Research Council of Canada grant to L.J.A.

\section{LITERATURE CITED}

Albright, L. J., Yang, C. Z., Johnson, S. (1993). Sub-lethal concentrations of the harmful diatoms, Chaetoceros concavicornis and $C$. convolutus increase mortality rates of penned Pacific salmon. Aquaculture 117: 215-225

Allen, A. (1978). Structure of gastrointestinal mucus glycoproteins and the viscous and gel-forming properties of mucus. Br. med. Bull. 34: 28-33

Aylward, M., Maddock, J., Dewland, P. (1980). Clinical evaluation of acetylcysteine in the treatment of patients with chronic obstructive bronchitis: a balanced double-blind trial with placebo control. Eur. J. respir. Dis. 61 (Suppl.) 111. $81-89$

Bell, G. R., Griffioen, W., Kennedy, O. (1974). Mortalities of pen-reared salmon associated with blooms of marine algae. In: Northwest Fish Cult. Conf., Seattle, WA, p. $58-60$

Bird, D. J., Eble, A. F. (1979). Cytology and polysaccharide cytochemistry of the gill of the American eel, Anguilla rostrata. Biol. Bull. 157: 104-111

Black, E. A. (1991). B.C. Ministry of Agriculture, Fisheries and Food studies on the management of salmon farming algae problems. In: Forbes, J. R. (ed.) Pacific coast research on toxic marine algae. Can. Tech. Rep. Hydrogr. Ocean Sc1. 135: $29-31$

Charman, J., Lopez-Vidriero, M. T., Keal, E., Reid, L. (1974). The physical and chemical properties of bronchial secretion. Br. J. Dis. Chest 68: 215-227

Cotgreave, I. A., Eklund, A., Larsson, K., Moldeus, P. W. (1987). No penetration of orally administered $\mathrm{N}$-acetyl-

Responsible Subject Editor: O. Kinne, Oldendorf/Luhe, Germany cysteine into bronchoalveolar lavage fluid. Eur. J. respir Dis. 70: $73-77$

Flora, S. D., Bennicelli, C., Camoirano, A., Serra, D., Romano, M., Rossi, G. A., Morelli, A., Flora, A. D. (1985). In vivo effects of $\mathrm{N}$-acetylcysteine on glutathione metabolism and on the biotransformation of carcinogenic and/or mutagenic compounds. Carcinogenesis 6: 1735-1745

Gaines, G. Taylor, F. J. R. (1986). A mariculturist's guide to potentially harmful marine phytoplankton of the northeast Pacific coast. Mar. Res. Sec. Br., B.C. Min. Environ., Victoria, p. $13-16$

Harrison, P. J., Waters, R. E., Taylor, F. J. R. (1980). A broad spectrum artificial medium for coastal and open ocean phytoplankton. J. Phycol. 16: 28-35

Horner, R. A., Postel, J. R., Rensel, J. E. (1991). Noxious phytoplankton blooms and marine salmon culture in Puget Sound, Washington. In: Forbes, J. R. (ed.) Pacific coast research on toxic marine algae. Can. Tech. Rep. Hydrogr. Ocean Sci. 135: 59-61

Lightowler, J. E., Lightowler, N. M. (1971). Comparative mucolytic studies on dithiothreitol, $\mathrm{N}$-acetylcysteine and L-cysteine on human respiratory mucus in vitro and their effects on the rate of flow of mucus in the exposed trachea of the rat on topical application. Arch. int. Pharmacodyn. Ther. 189: 53-58

Majima, Y., Hirata, K., Takeuchi, K., Hattori, M., Sakakura, Y. (1989). Effects of orally administered drugs on dynamic viscoelasticity of human nasal mucus. Am. Rev. respir. Dis 141: 79-83

Martin, R., Mitchell, L., Marriott, C. (1980). The effect of mucolytic agents on the rheological and transport properties of canine tracheal mucus. Am. Rev. respir. Dis. 121. $495-500$

Powell, M. D., Speare, D. J., Burka, J. F. (1992). Fixation of mucus on rainbow trout (Oncorhynchus mykiss Walbaum) gills for light and electron microscopy. J. Fish. Biol. 41 813-824

Servin, A., Goulinet, L. S., Renault, H. (1988). Pharmacokinetics of cysteine ethyl ester in rat. Xenobiotica 18: 839-847

Sheffner, A. L. (1963) The reduction in vitro in viscosity of mucoprotein solutions by a new mucolytic agent, N-acetyl-L-cysteine. Ann. N.Y. Acad. Sci. 106: 298-310

Ueno, O., Lee, L. N., Wagner, P. D. (1989). Effects of N-acetylcysteine on gas exchange after methcholine challenge and isoprenaline inhalation in the dog. Eur. Respir J. 2: $238-246$

Utermöhl. H. (1958). The improvement of quantitative phytoplankton methodology. Mitt. int. Verein. Limnol. 9: $1-39$

Walters, C. R., Marriott, C., Turner, R. J. (1985). The use of SEM to evaluate the effects of mucolytic agents on mucus gel structure. J. Pharm. Pharmacol. 37 143-152

Yang, C. Z., Albright, L. J. (1992). Effects of the harmful diatom, Chaetoceros concavicornis on respiration of rainbow trout Oncorhynchus mykiss. Dis. aquat. Org. 14: 105-114

Ziment, T. I. (1978). Respiratory pharmacology and therapeutics. Saunders, Philadelphia, p. 41-60

Manuscript first received: February 23, 1994

Revised version accepted: July 27, 1994 